\title{
IAA HIGHLIGHTS
}

\section{Dear Reader,}

Over the past few days, I was often asked what the highlight of this year's IAA was. People expected me to say a snazzy sports car like the Opel Monza or the limited-edition Porsche 918 Spyder. But for me, the real highlights of the show were the many different technology trends. Two of them are the productionready all-electric car and automated driving.

At Frankfurt's last Motor Show two years ago, attention was still firmly focused on studies of small electric vehicles and single- or two-seater city cars. Shortly after the IAA, compact electric cars were expected to herald a new and endless age of electric mobility. But this exuberant euphoria was soon followed by disillusionment. The Opel Ampera was particularly badly affected by car buyers' hesitance. In the meantime however, the fleet of electric cars has grown to massproduction proportions, and the spotlight at the IAA 2013 was clearly on newcomers like the BMW i3, VW E-Golf and Smart Electric Drive. And it is clear that OEMs are pursuing quite different strategies. BMW has designed a completely new car from scratch to accommodate battery power and lightweight design, whereas Volkswagen and Daimler have taken an existing - and therefore fully mature - car and "merely" transplanted an electric heart. The different approaches being applied to the topic of electric mobility are shown in two interesting articles by FEV and ika as part of our main topic from page 4 onwards.

The second important trend at the show was autonomous driving. Various terms for this could be found at the IAA: Some referred to it as piloted driving, others called it partially or highly automated driving, while some chose the term assisted driving. Mono or stereo cameras and radar or laser scanners monitor the traffic situation around the vehicle and use sophisticated algorithms to determine the best way to drive. Bosch and Continental are in agreement that driving will be partially automated by 2016 , highly automated by 2020 and fully autonomous from 2025. Drivers will then be free to chat on their smartphones or send tweets, text messages and e-mails. But autonomous driving should not only serve the need for even more applications of consumer electronics and provide more leisure time or even working time in the car. It will be far more important to use it to improve road safety. According to the United Nations, the number of road fatalities worldwide is expected to rise from the current $1.3 \mathrm{mil}$ lion to 1.9 million by 2020 . The aim must be to slow down this increase as much as possible by using assistance systems. We can only hope that this important issue does not suffer the same fate as the hype surrounding electric mobility - and that we will hear a lot more about it at the next IAA in two years' time.

Best regards,

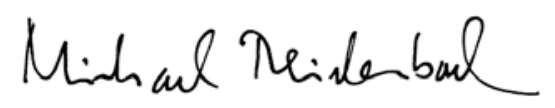

DIPL.-ING. MICHAEL REICHENBACH,

Vice-Editor in Chief

Wiesbaden, 23 September 2013

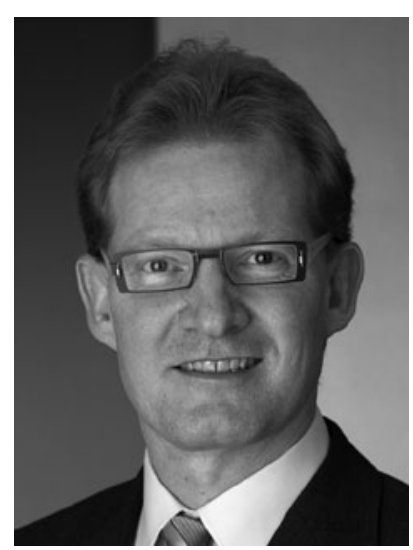

